\title{
The Effect of Salicylate on Liver Glycogen in the Rat
}

\author{
By M. J. H. SMITH \\ Department of Chemical Pathology, King's College Hospital Medical School, London, S.E. 5
}

(Received 5 January 1954)

The injection of salicylate into normal rats has been observed to cause a marked depletion of the liverglycogen level within 4-7 hr. (Lutwak-Mann, 1942; Smith, Meade \& Bornstein, 1952). The fall was temporary and partial replacement of the liver glycogen had occurred in $24 \mathrm{hr}$. Lutwak-Mann (1942) reported that after $24 \mathrm{hr}$. the liver-glycogen level of some of the salicylate-treated animals was greater than that of the control animals.

In the experiments of Smith et al. (1952) the rats were given unrestricted access to food, which was withdrawn immediately before the salicylate injection. The animals may have differed in the amount of food present in the stomach at the time of withdrawal and the fasting period of some rats may have been longer than others. It appeared possible to overcome this difficulty after Barnes (1953) had shown that rats could be trained to eat a single daily feed of $1 \mathrm{hr}$. duration. The effect of salicylate on the liver glycogen and blood glucose of rats maintained on such a regimen was therefore investigated. The salicylate was given immediately after the feed, and liver glycogen and blood glucose were estimated in groups of animals killed during the subsequent $24 \mathrm{hr}$. In order to assess the influence of the adrenal, similar experiments were performed on adrenalectomized rats and on adrenalectomized rats receiving adequate maintenance doses of cortisone.

\section{EXPERIMENTAL}

Animals. Male rats of the Wistar strain weighing 200$250 \mathrm{~g}$. and maintained on a diet of cubes (Medical Research Council Diet 41) were used.

Analytical methods. Liver glycogen was measured by the method of Good, Kramer \& Somogyi (1933) on 80-100 mg. portions of liver taken as nearly as possible from anatomically similar lobes immediately after the rats had been killed by stunning. The glucose in the final stage of the glycogen estimation and also the blood glucose were measured by the method of Nelson (1944). Blood salicylate was determined by the method of Smith \& Talbot (1950). All the results are expressed as means, together with the standard deviation.

\section{General arrangement of experiments}

Effect of salicylate on the liver glycogen and blood glucose of normal rats on single-meal regimen. The rats were given the cube diet from 9 to 10 a.m. each day, and had access to water at all times. After an initial loss in weight during the first week they adjusted themselves to the new conditions and at the end of 3 weeks showed a normal gain in weight. Forty-two rats were divided into seven groups, containing 5-7 rats, and immediately after the feed the first group was killed by stunning. Three of the remaining groups were given an intraperitoneal injection of $1 \mathrm{ml} .0 .9 \%(\mathrm{w} / \mathrm{v}) \mathrm{NaCl}$ and the other three groups an intraperitoneal injection of $100 \mathrm{mg}$. of sodium salicylate in $1 \mathrm{ml}$. of water. One salinetreated and one salicylate-treated group were killed by stunning 6, 12 and $24 \mathrm{hr}$. after the start of the experiment. All the animals were fasted throughout the experiment.

Blood-glucose estimations were made on tail-vein samples at the times indicated in Table 2, and liver glycogen and blood salicylate were measured on specimens obtained im. mediately after the death of the animals.

The effect of successive daily doses of sodium salicylate on the liver glycogen was investigated in two groups of 7 rats trained on the single-meal regimen. One group received an intraperitoneal injection of $1 \mathrm{ml} .0 .9 \%(\mathrm{w} / \mathrm{v}) \mathrm{NaCl} \mathrm{im}$ mediately after each feed and the other an injection containing $100 \mathrm{mg}$. of sodium salicylate in $1 \mathrm{ml}$. water. The animals received the injections for 10 days and were fasted for $24 \mathrm{hr}$. after the last injection and then killed.

Effect of salicylate on the liver glycogen and blood glucose of adrenalectomized rats. The rats were given access to the cube diet from 9 to 10 a.m. and 4 to 5 p.m. each day, and maintained until their weight increase became normal. Two meals each day were given instead of the single daily feed, because it was considered that the latter regimen with its $23 \mathrm{hr}$. fasting period was too severe for adrenalectomized rats. The animals were bilaterally adrenalectomized, given continuous access to cubes for $12 \mathrm{hr}$. after the operation and maintained on $0.45 \%(\mathrm{w} / \mathrm{v}) \mathrm{NaCl}$ and the two-meal regimen for 7 days. They were then divided into seven groups and the first experiment repeated on them.

Effect of salicylates on liver glycogen and blood glucose in adrenalectomized rats maintained on cortisone. The previous experiment was repeated except that after adrenalectomy each rat received $1 \mathrm{mg}$. of cortisone acetate daily as a subcutaneous injection of $0.1 \mathrm{ml}$. of a 1 in 5 dilution of cortisone acetate suspension (Merck) immediately before each feed. Ingle, Beary \& Purmalis (1953) employed the equivalent of only $\mathbf{0 . 1} \mathrm{mg}$. of hydrocortisone daily to maintain adrenalectomized rats, but previous work (Smith, 1952) had indicated that the Wistar rats used in the present experiments were far less sensitive to cortisone than the Sprague-Dawley rats used by the American workers.

\section{RESULTS}

The effects of salicylate on the liver glycogen and blood glucose of normal rats on single-meal regimen

The liver glycogen and blood salicylate results are given in Table 1 and the blood-glucose results in Table 2. Table 1 shows that the administration of 
Table 1. The effect of salicylate on the liver glycogen of normal rats on single-meal regimen

Mean values \pm standard error (number of rats in brackets) are given for liver-glycogen and plasma-salicylate levels.

\begin{tabular}{|c|c|c|c|c|c|}
\hline \multirow{2}{*}{$\begin{array}{l}\text { Time after } \\
\text { injection } \\
\text { (hr.) }\end{array}$} & \multicolumn{2}{|c|}{$\begin{array}{l}\text { Liver glycogen content } \\
\text { (g./100 g. wet wt.) }\end{array}$} & \multirow{2}{*}{$\begin{array}{c}\text { Plasma } \\
\text { salicylate } \\
\text { (mg./100 ml.) }\end{array}$} & \multicolumn{2}{|c|}{$\begin{array}{l}\text { Comparison of liver-glycogen } \\
\text { results for groups } A \text { and } B\end{array}$} \\
\hline & $A$, saline injected & $B$, salicylate injected & & $t$ & $P$ \\
\hline $\begin{array}{r}0 \\
6 \\
12 \\
24\end{array}$ & $\begin{array}{r}3.44 \pm 0.33(6) \\
10 \cdot 24 \pm 1 \cdot 23(6) \\
10.45 \pm 1.46(6) \\
1.91 \pm 0.90(5)\end{array}$ & $\begin{array}{c}2 \overline{2} \\
2 \cdot 86 \pm 0 \cdot 69(6) \\
4 \cdot 72 \pm 1 \cdot 15(6) \\
5 \cdot 10 \pm 1 \cdot 82(7)\end{array}$ & $\begin{array}{c}-\overline{42}(6) \\
25 \pm 5(6) \\
14 \pm 3(7)\end{array}$ & $\begin{array}{r}12 \cdot \overline{7763} \\
5 \cdot 0742 \\
3 \cdot 5817\end{array}$ & $\begin{array}{l}\overline{-} \\
0.001 \\
0.001 \\
0.01\end{array}$ \\
\hline
\end{tabular}

Table 2. The effect of salicylate on the blood glucose of normal rats on single-meal regimen

Mean values \pm standard error (number of rats in brackets) are given for blood-glucose levels.

\begin{tabular}{|c|c|c|c|c|}
\hline \multirow{2}{*}{$\begin{array}{c}\text { Time after injection } \\
\text { (hr.) }\end{array}$} & \multicolumn{2}{|c|}{ Blood glucose (mg./100 ml.) } & \multicolumn{2}{|c|}{$\begin{array}{l}\text { Comparison of blood-glucose } \\
\text { results for groups } A \text { and } B\end{array}$} \\
\hline & $A$, saline injected & $B$, salicylate injected & $t$ & $P$ \\
\hline Before feeding & $75 \cdot 6 \pm 5 \cdot 9(5)$ & $71 \cdot 8 \pm 8 \cdot 0(5)$ & $0 \cdot 8491$ & 0.5 \\
\hline $\begin{array}{l}\text { After feeding } \\
\quad 0 \\
0 \cdot 5 \\
1 \\
1 \cdot 5 \\
2 \\
3 \\
6 \\
12 \\
24\end{array}$ & $\begin{array}{l}90 \cdot 5 \pm 8 \cdot 0(4) \\
94 \cdot 0 \pm 4 \cdot 4(4) \\
93 \cdot 0 \pm 5 \cdot 4(4) \\
94 \cdot 0 \pm 4 \cdot 1 \text { (4) } \\
87 \cdot 8 \pm 2 \cdot 8(4) \\
86 \cdot 3 \pm 4 \cdot 4(4) \\
84 \cdot 0 \pm 0 \cdot 8(4) \\
78 \cdot 5 \pm 2.5(4) \\
71 \cdot 0 \pm 2 \cdot 2(4)\end{array}$ & $\begin{array}{l}91 \cdot 2 \pm 5 \cdot 2(5) \\
91 \cdot 8 \pm 5 \cdot 5(5) \\
84 \cdot 0 \pm 7 \cdot 0(5) \\
83 \cdot 2 \pm 6 \cdot 6(5) \\
77 \cdot 2 \pm 7 \cdot 8(5) \\
76 \cdot 4 \pm 9 \cdot 0(5) \\
84 \cdot 5 \pm 4 \cdot 4(5) \\
81 \cdot 8 \pm 2 \cdot 1(5) \\
81 \cdot 2 \pm 4 \cdot 9(5)\end{array}$ & $\begin{array}{l}0 \cdot 1588 \\
0 \cdot 6427 \\
2 \cdot 1125 \\
2 \cdot 8517 \\
2 \cdot 5395 \\
1 \cdot 9439 \\
0 \cdot 2229 \\
2 \cdot 1689 \\
3 \cdot 8515\end{array}$ & $\begin{array}{c}0.9 \\
0.6 \\
<0.1>0.05 \\
<0.05>0.02 \\
<0.05>0.02 \\
0.1 \\
0.9 \\
0.1 \\
0.01\end{array}$ \\
\hline
\end{tabular}

Table 3. The effect of salicylate on liver glycogen and blood glucose in adrenalectomized rats on two-meal regimen

Mean values \pm standard error (number of rats in brackets) are given for the blood-glucose, plasma-salicylate and liverglycogen levels.

$\begin{gathered}\text { Time after } \\ \text { injection } \\ \text { (hr.) }\end{gathered}$
0
$\mathbf{6}$
12
$\mathbf{2 4}$

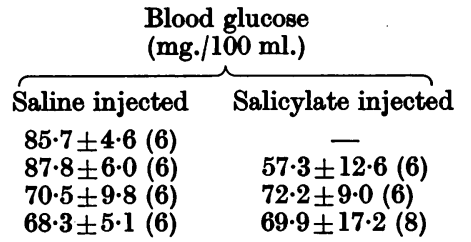

\begin{tabular}{|c|c|c|}
\hline \multicolumn{2}{|c|}{$\begin{array}{c}\text { Liver glycogen } \\
\text { (g./100 g. wet wt.) }\end{array}$} & \multirow{2}{*}{$\begin{array}{c}\text { Plasma } \\
\text { salicylate } \\
\text { (mg./100 ml.) }\end{array}$} \\
\hline Saline injected & Salicylate injected & \\
\hline $\begin{array}{l}0.51 \pm 0.1(6) \\
1.88 \pm 0.6(6) \\
0.12 \pm 0.05(6) \\
0\end{array}$ & $\begin{array}{c}\overline{0} \\
0.17 \pm 0.06(6) \\
0.05 \pm 0.01 \text { (6) } \\
0\end{array}$ & $\begin{array}{c}46 \cdot 0 \pm 5 \cdot 1(6) \\
43 \cdot 0 \pm 10 \cdot 7(6) \\
16 \cdot 0 \pm 4 \cdot 3(8)\end{array}$ \\
\hline
\end{tabular}

Table 4. Effect of salicylate on liver glycogen and blood glucose of adrenalectomized rats on two-meal regimen and maintained on cortisone

Mean values \pm standard error (number of rats in brackets) are given for blood-glucose and liver-glycogen levels.



\begin{tabular}{|c|c|}
\hline \multicolumn{2}{|c|}{$\begin{array}{l}\text { Liver glycogen } \\
\text { (g./100 g. wet wt.) }\end{array}$} \\
\hline $\begin{array}{l}A, \text { saline } \\
\text { injected }\end{array}$ & $\begin{array}{c}B \text {, salicylate } \\
\text { injected }\end{array}$ \\
\hline $\begin{array}{l}1.59 \pm 0.38(6) \\
2 \cdot 64 \pm 0.9(6) \\
0.32 \pm 0.22(8)\end{array}$ & $\begin{array}{c}\overline{0.09} \overline{0.11}(6) \\
0.79 \pm 0.57(9)\end{array}$ \\
\hline
\end{tabular}

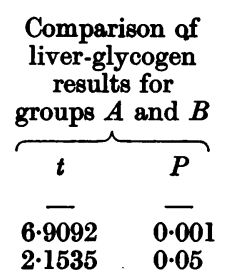


salicylate immediately after feeding prevented the normal deposition of liver glycogen observed in the control animals at 6 and $12 \mathrm{hr}$., while after $24 \mathrm{hr}$. the liver glycogen in the salicylate-treated rats was significantly higher than in the control animals. Table 2 shows that immediately after feeding there was no difference between the control and salicylatetreated groups, but that at $1,1.5$ and $2 \mathrm{hr}$. after the injection the blood glucose of the salicylate-treated group was significantly lower than the control. At 3,6 and $12 \mathrm{hr}$. the blood-glucose values did not differ, but at $24 \mathrm{hr}$. the blood glucose of the salicylate-treated group was significantly higher than the control.

Daily injections of sodium salicylate for 10 days to normal rats on the single-meal regimen were found to produce a significantly higher content of liver glycogen after a $24 \mathrm{hr}$. fast than in similar animals injected with saline. Liver-glycogen levels of $2 \cdot 67 \pm 0.57(7)$ and $5 \cdot 71 \pm 1 \cdot 36(7)$ g./100 g. wet weight were obtained for saline-injected and salicylateinjected rats, respectively $(t=5 \cdot 4536 ; P=0.001)$.

Effect of salicylate on the liver glycogen and blood glucose of adrenalectomized rats on two-meal regimen

The liver glycogen, blood-glucose and bloodsalicylate results are given in Table 3 and show that the administration of sodium salicylate prevented the deposition of liver glycogen produced in the control animals and also caused a significant fall in the blood-glucose concentration $(P<0.05)$ only at $6 \mathrm{hr}$. However, after $24 \mathrm{hr}$. the liver glycogen of both groups was zero and there was no significant difference in the blood-glucose concentrations. These results indicated that the presence of the adrenals was essential for salicylates to produce a higher $24 \mathrm{hr}$. fasting level of liver glycogen.

Effect of salicylate on the liver glycogen and blood glucose of adrenalectomized rats on two-meal regimen and receiving a daily maintenance dose of cortisone

The results given in Table 4 show that salicylate, as in the previous experiment, prevented the deposition of liver glycogen and caused a significant fall in the blood glucose at $6 \mathrm{hr}$.; at $24 \mathrm{hr}$., however, the liver-glycogen and blood-glucose concentrations of the salicylate-treated group were significantly higher than those of the saline-treated controls.

\section{DISCUSSION}

The results show that the initial effect of salicylate is to prevent the deposition of liver glycogen which normally occurs after a meal and to produce a fall in blood-glucose concentration. If the observations are continued for $24 \mathrm{hr}$., however, salicylate causes an increased liver-glycogen content and bloodglucose concentration.

There are four possible mechanisms to explain these effects of salicylate: $(a)$ delayed absorption of food from the gut; $(b)$ interference with the conversion of blood glucose into liver glycogen; (c) disturbance of the normal functions of the adrenal glands; and $(d)$ increased utilization of glucose in the tissues.

Examination of the abdominal viscera of the normal rats did not reveal any gross differences in the amount of food in the various parts of the gut between the saline-treated and salicylate-treated animals killed at the stated times. In the adrenalectomized rats, whether or not maintained on cortisone, the passage of food through the alimentary tract appeared to be greatly delayed in the salicylate-treated animals. A delay in gastric emptying caused by salicylate would provide an adequate explanation of the present results and a radiological investigation of the effect of salicylate on the passage of a barium meal in normal rats is being made.

If salicylates interfered in some way with the conversion of blood glucose into liver glycogen, an increased blood-glucose concentration should have coincided with the decreased liver-glycogen content of the salicylate-treated group. The reverse was found and this mechanism is therefore not valid.

The influence of the adrenals upon the liverglycogen level has been recognized in recent years because the effects of a number of entirely different procedures, such as hypoxia, on liver glycogen are not observed in adrenalectomized animals (cf. Barnes, 1953). The effects of salicylate in preventing the deposition of liver glycogen at $6 \mathrm{hr}$. and in causing a fall in blood glucose between 1 and $2 \mathrm{hr}$. in the normal rats are not explicable in terms of stimulation of the adrenal cortex, but the $24 \mathrm{hr}$. rise in both liver glycogen and blood sugar could be a reflexion of such a stimulation. However, although the $24 \mathrm{hr}$. effects of salicylate on liver glycogen and blood glucose were not found in adrenalectomized rats they were observed in similar animals receiving an adequate maintenance dose of cortisone. These findings support the concept of Ingle (1943) that the adrenocortical hormones play a supporting role in metabolic adjustments to some types of extraadrenal stimuli and that an increased secretory activity of the adrenal cortex is not necessary to produce the response. Thus the presence of an adequate amount of adrenocortical hormones, i.e. a state of eucorticalism, rather than a stimulation of the adrenal cortex, is sufficient for the $24 \mathrm{hr}$. effects of salicylate on liver glycogen and blood glucose to be demonstrated. 
An increased rate of glucose utilization in the tissues could provide a possible explanation of the results but there is no direct evidence that salicylate has such an effect. However, Cochran (1952) reported that salicylate caused a marked and progressive increase in oxygen consumption in man, and Meade (personal communication) has found the same effect in the rat. The increased oxygen consumption suggested that perhaps salicylate, like the dinitrophenols, may interfere with oxidative phosphorylation reactions. If salicylate inhibited the production of high-energy phosphate bonds, then during the initial phase after giving salicylate, increasing amounts of substrate may be sacrificed to supply the energy needed for the increasingly inefficient phosphorylating processes. The low levels of liver glycogen and blood glucose may be indications of this demand for energy sources.

When the acute phase of salicylate action is over and phosphorylating processes can proceed normally, there may be an excess of metabolites remaining from the initial period of increased oxidative activity. These may be converted into liver glycogen and blood glucose and such a mechanism may provide an explanation of the increases in these substances $24 \mathrm{hr}$. after the salicylate has been given. This hypothesis was proposed by Barnes (1953) to explain essentially similar effects produced on the liver glycogen of rats by the injection of dinitro-o-cresol, a compound known to cause an increased oxygen consumption and inhibition of uptake of inorganic phosphate in respiring mitochondrial preparations (Loomis \& Lipmann, 1948). In order to obtain further information concerning a possible action of salicylate on oxidative phosphorylation the in vitro effects of salicylate on glycogen synthesis and oxygen uptake in isolated rat diaphragm are being studied.

\section{SUMMARY}

1. The effect of sodium salicylate on the liver glycogen and blood glucose of normal, adrenalectomized and adrenalectomized rats maintained on cortisone, are described.

2. In the normal and adrenalectomized rats maintained on cortisone, a single dose of salicylate causes an initial impairment of the deposition of liver glycogen and a fall in blood glucose, but after $24 \mathrm{hr}$. the levels of these substances are higher than in control animals.

3. In adrenalectomized rats the initial effect of salicylate on liver glycogen and blood glucose is similar, but no recovery occurs after $24 \mathrm{hr}$.

4. Some possible mechanisms to explain these effects are discussed.

I wish to express my thanks to Miss E. Quilley and Miss M. Sandiford for technical assistance, and to the Board of Governors of King's College Hospital for a grant towards the cost of the work.

\section{REFERENCES}

Barnes, J. M. (1953). Biochem. J. 54, 148.

Cochran, J. B. (1952). Brit. med. J. 2, 964.

Good, C. A., Kramer, H. \& Somogyi, M. (1933). J.biol.Chem. $100,485$.

Ingle, D. J. (1943). Amer. J. Physiol. 138, 577.

Ingle, D. J., Beary, D. F. \& Purmalis, A. (1953). Endocrinology, 53, 30.

Loomis, W. F. \& Lipmann, F. (1948). J. biol. Chem. 173, 807.

Lutwak-Mann, C. (1942). Biochem. J. 36, 706.

Nelson, N. (1944). J. biol. Chem. 153, 375.

Smith, M. J. H. (1952). Biochem. J. 52, 649.

Smith, M. J. H., Meade, B. W. \& Bornstein, J. (1952). Biochem. J. 51, 18.

Smith, M. J. H. \& Talbot, J. M. (1950). Brit. J. exp. Path. 81, 65. 